\title{
WORK RELATED MUSCULOSKELETAL DISORDERS
}

\author{
AMONG EGYPTIAN DENTISTS
}

WORKING AT FACULTY OF DENTISTRY-AIN SHAMS

\section{UNIVERSITY}

\author{
By \\ El Hosseini DM, Momen MA and Wassif GO \\ Department of Occupational and Environmental Medicine, Faculty of Medicine, Ain Shams University. \\ Corresponding author: El Hosseini DM:doaa.elhussiney@med.asu.edu.eg
}

\begin{abstract}
Introduction: The prevalence of musculoskeletal complaints among dentists is high. The symptoms might impair work capacity and the future possibility to stay in the profession. In Egypt, data about the prevalence and risk factors of this problem are scanty. Aim of work: To estimate the prevalence of musculoskeletal disorders (MSDs) and its distribution among dental staff, house officers and students at faculty of Dentistry, to find out the influence of personal and job characteristics, physical and psychological risk factors at work on the occurrence of MSDs and to detect the impact of MSDs on participants' life. Materials and methods: A cross sectional study was carried out among (403) participants. A self-administered questionnaire that included information about: personal and job characteristics, a version of Standard Nordic Questionnaire for occurrence of MSDs and modified version of Demand/Control model Questionnaire from Karasek for psychosocial factors. Results: The overall MSDs prevalence among participants was $66.7 \%$, in which $29.3 \%$ had chronic complaints. Neck and shoulder pain were the most prevalent sites of complaint reported by $66.5 \%$ and $61.8 \%$ of the subjects respectively, followed by low back pain and wrist pain $(59.3 \%, 46.2 \%$, respectively). The severity of MSDs forced $24.2 \%$ of respondents to take analgesic, $30.1 \%$ to reduce their daily activities, and $8.6 \%$ to go on sick leave. Dental staff significantly had the highest prevalence of MSDs compared to dental students and house officers. Older age participants were more prone to MSDs compared to younger ones; female respondents had higher MSDs than male but without statistical significance. As regard the physical factors at work: the use of vibration tool, excessive arm elevation and prolonged standing / sitting were significantly associated with increase in the prevalence of MSDs. Also psychosocial factors: as poor job control was significantly associated with the development of MSDs while high work demand didn't. Conclusion: Work related musculoskeletal disorders are significant occupational health problems among both dentists and dental students. Their medical consequences justify extensive preventive efforts. Specific occupational health education programs, including ergonomic workplace adaptation should be implemented.
\end{abstract}

Key words: Musculoskeletal disorders, Dentists, Ergonomics, Risk factors and Sickness absenteeism. 


\section{Introduction}

Musculoskeletal disorders (MSDs) have become increasingly common worldwide during the past decades. They are common cause of work-related disability among workers with substantial financial consequences particularly in severe cases due to frequent absence and early retirement (Andersson, 1999). MSDs are characterized by the presence of discomfort, disability or persistent pain in the joints, muscles, tendons, and other soft parts, caused or aggravated by repeated movements and prolonged awkward or forced body postures (Morse et al., 2007).

Dentistryisaprofession thatgenerally produces various musculoskeletal pains and soreness, which are slow to appear; consequently, the symptoms are usually ignored until they become chronic and permanent lesions become evident (Diaz et al., 2010). The higher rates of MSDs among dentists can be attributed to various physiological and ergonomic factors related to the profession (Hayes et al., 2009). Overstrained and awkward postures, repetitiveness of different joint movements, use of high frequency vibration tools have been identified as risk factors (Szymańska, 2002).
Dentists also face the psychosocial risk factors of high job demands, low job control which can increase the risk of developing MSDs (Hakkanen et al., 2001). Among the wide range of musculoskeletal disorders, back pain was the most common among dentists, followed by neck pain, high muscle tension on the trapezoids, and carpel tunnel syndrome (Yousef and Al-Zain, 2009).

The impact of this occupational health problem is quite high worldwide. A systemic review suggested that the prevalence of general muscle pain in dentists can range between (64\%) to (93\%) (Udoye and Aguwa, 2007).In a survey of Danish dentists, $50 \%$ and $65 \%$ reported a one year prevalence of lower back pain and neck/shoulder pain, respectively (Samotoi et al., 2008). The majority of the studies on work related MSDs among dental workers were conducted in the developed world. In developing countries; little awareness has been paid to the prevalence and effect of MSDs (Shikdar and Sawaqed, 2004). In particular; a few studies have been conducted in Egypt; Hassan and his coworkers ( 2017), reported that $88.4 \%$ of the Egyptian dentists working at Menia University Hospital complained 
from MSDs, another study conducted in Sharkia found that the overall prevalence of MSDs among dentists was $66.7 \%$ (Ahmed and Orabi,2017). Risk factors are expected to be different in different types of dental clinic in Egypt, there for; it is crucial to estimate the prevalence of MSDs and identify the risk factors associated with their occurrence. This would help to develop recommendations and strategies for prevention.

\section{Aim of work}

1) To estimate the prevalence of musculoskeletal disorders (MSDs) and its distribution among dental staff, house officers and students at faculty of Dentistry, 2) To find out the influence of personal and job characteristics, physical and psychological risk factors at work on the occurrence of MSDs and 3) To detect the impact of MSDs on participants' life.

\section{Materials and methods}

Study design: It is an analytical cross sectional study.

\section{Place and duration of the study:} The study was conducted at faculty of Dentistry, Ain Shams University; during the period from March to December, 2018.
Study sample: Four hundred and sixteen (416) participants were randomly selected. Nearly 97\% (403) of them responded. The reasons for non-participation were lack of time and refusals. Dentists (students, house officers and staff members) of any age who were working at least for 1 year were included, while those who complained of muscular pain before starting work were excluded from the study.

Sample size was calculated using Open Epi. Version 3, open source calculator based on a prevalence of MSDs of $50 \%$ among dentists (Samotoi et al., 2008) which would yield the largest sample size of (384). Sample size was increased to include (416) dentists to account for nonresponse among dentists, taking into consideration that the sample size was calculated with confidence level of $95 \%$ and a margin of error $\pm 5 \%$. Our sample was (403) participants consisted of (114) dental staff, (118) house officers and (171) dental students.

\section{Study methods:}

-A self-administered questionnaire; the questionnaire was specially developed for this study and its content validation was carried out based on 
previous literatures. A pilot study was conducted first among 10 dentists to test for the comprehensibility and relevance of the questionnaire. It contained four sections as the following;

1- Section one: included information about personal characteristics such as: age, gender and smoking. Body Mass Index (BMI) was calculated by dividing the weight in $\mathrm{Kg}$ over the square height in meter. Occupational history included questions about job position, duration of employment, working hours and number of patients examined per day.

2- Section two: concerned with the physical work load such as: repetitive movements, awkward working postures in which the back is bent or twisted, prolonged sitting or standing, and strenuous arm positions like working with hands in excessive tightening or arm abduction and elevated arms, and use of vibrating tools. A four-point scale was used with ratings 'seldom or never', 'now and then', 'often', and 'always' during a regular workday. The answers 'often' and 'always' were classified as high exposure.

3- Section three: modified version of Demand/Control Model
Questionnaire from Karasek, which investigates the psychosocial aspects at work and distinguished two principle areas; job demand and job control (Karasek et al, 1998). Job demand was measured by a group of questions which included working fast and hard, excessive workload and insufficient time to complete duties. Lack of control was measured by another group of questions related to creativity, task variety, learning new things and amount of repetitive work. The questions were scored on a fourpoint scale, yielding a sum score for job demands and control. In the statistical analysis, scores above the median value considered as the presence of psychosocial risk.

4- Section four: focused on the presence of MSDs, including the body region(s), and the consequences of the symptoms using the Standardized Nordic Questionnaire which is a valid and reliable screening and surveillance questionnaire for measuring MSDs ( Kuorinka et al, 1987 ) .The questionnaire included the following points: (i) Musculoskeletal complaint of back, neck, shoulder or hand/wrist was defined as pain in the past 12 months, 
which had continued for at least a few hours during the past 12 months, (ii) Chronic musculoskeletal pain in the past 12 months, referred to a complaint that was present almost every day in the preceding 12 months with a minimal presence for at least 1 month, (iii) Impact of musculoskeletal disorders (MSDs) on participants' life (job performance, daily activities, analgesic taking and sickness absenteeism).

\section{Consent}

Informed consent was obtained from each participant sharing in the study after explaining the purpose of the study and assuring confidentiality.

\section{Ethical approval}

Administrative approval was obtained from the Head of the department of Community Medicine at Ain Shams University.

\section{Data management}

Data was collected, coded and entered then analyzed using SPSS program version 21. Quantitative data were presented as mean and standard deviation. Qualitative data were presented as number and percentage. Chi-square test was used to compare qualitative data in two or more different groups. Also, Fisher's exact test was used to examine the relationship between two qualitative variables when the expected count is less than 5 in more than $20 \%$ of cells. A p value $\leq 0.05$ is considered as statistically significant

\section{Result}

Table (1): Distribution of the study population according to personal and job characteristics $(\mathrm{No}=403)$.

\begin{tabular}{|l|c|}
\hline \multicolumn{1}{|c|}{ Variables } & No(\%) \\
\hline Age(years): Mean \pm SD $26.6 \pm 7.1$ \\
\hline Gender: & $209(51.9 \%)$ \\
\hline Males & $194(48.1 \%)$ \\
\hline Females & $321(79.7 \%)$ \\
\hline Smoking status: & $82(20.3 \%)$ \\
\hline NO & Body Mass Index :Mean \pm SD $25.2 \pm 5.05$ \\
\hline Yes \\
\hline \multicolumn{2}{|c|}{} \\
\hline Job description:
\end{tabular}




\begin{tabular}{|l|c|}
\hline Students & $171(42.4 \%)$ \\
\hline House officers & $118(29.3 \%)$ \\
\hline Staff & $114(28.3 \%)$ \\
\hline Duration of practice / years: & \\
\hline Less than 10 years & $351 \quad(87.1 \%)$ \\
\hline 10 years or more & $52(12.9 \%)$ \\
\hline Working hours/week & $207 \quad(51.4 \%)$ \\
\hline Less than 40 hours/week & $196 \quad(48.6 \%)$ \\
\hline 40 hours/week or more & $229 \quad(56.8 \%)$ \\
\hline Number of patients seen per day: & $174 \quad(43.2 \%)$ \\
\hline Less than 10 patients/day & \\
\hline 10 patients or more/day & \\
\hline
\end{tabular}

Table (1) showed that males represented (51.9\%) compared to females $(48.1 \%)$. Only (20.3\%) of participants were smoking, dental students accounted to $(42.4 \%)$ of the study subjects and the remaining were house officers (29.3\%) and staff $(28.3 \%)$. The majority of the study participants $(87.1 \%)$ practiced dentistry from less than 10 years, while only few of them $(12.9 \%)$ practiced 10 years or more. Almost half of the study group (48.6\%) worked 40 hours weekly or more and $(43.2 \%)$ treated 10 patients or more in their daily practice.

\section{Table (2): Prevalence of musculoskeletal complaints among the study participants $(\mathrm{No}=403)$.}

\begin{tabular}{|l|c|c|}
\hline \multicolumn{1}{|c|}{ Musculoskeletal complaints } & No & (\%) \\
\hline Overall MSDs symptom in the past 12 months & 269 & $66.7 \%$ \\
\hline Chronic complaints (more than 1 month) & 118 & $29.3 \%$ \\
\hline Type of MSD disorders (\#) & & \\
\hline Neck stiffness & 268 & $66.5 \%$ \\
\hline Shoulder pain & 249 & $61.8 \%$ \\
\hline Low back pain & 239 & $59.3 \%$ \\
\hline Hand/wrist pain & 186 & $46.2 \%$ \\
\hline
\end{tabular}

(\#) More than one MSD may be found in the same participant 
The prevalence of musculoskeletal complaints among dentists is presented in Table (2); about two thirds of the participants $(66.7 \%)$ were found to be suffering from MSDs and nearly one third (29.3\%) of them had chronic symptoms that lasts for more than one month. Neck stiffness and shoulder pain were the most prevalent musculoskeletal complaints, as reported by $(66.5 \%)$ and $(61.8 \%)$ of the subjects respectively.

Table (3): Consequences of MSDs on life activities of the suffering study participants $(\mathrm{No}=\mathbf{2 6 9})$

\begin{tabular}{|l|c|c|}
\hline \multicolumn{1}{|c|}{ Effect of MSDs } & No & (\%) \\
\hline Reduction in work performance & 65 & 24.2 \\
\hline Reduction in daily activities & 81 & 30.1 \\
\hline Pain preventing going to work & 23 & 8.6 \\
\hline Taking analgesics & 65 & 24.2 \\
\hline Physiotherapy & 16 & 5.9 \\
\hline Surgical intervention & 12 & 4.5 \\
\hline
\end{tabular}

Table 3 showed that nearly quarter of the respondents $(24.2 \%)$ reported that their work performance was altered, and almost one third (30.1\%) said that they were unable to practice to their regular daily activities due to pain. The severity of MSDs forced (24.2\%) respondents to take analgesics and (8.6\%) to go on sick leave, $(5.9 \%)$ of the respondents needed physiotherapy and $(4.5 \%)$ of them needed surgical intervention to overcome the pain. 
Table (4): Association between MSDs in the past 12 months, personal and job characteristics.

\begin{tabular}{|c|c|c|c|c|c|}
\hline \multirow{2}{*}{$\begin{array}{l}\text { Personal and job } \\
\text { characteristics }\end{array}$} & \multicolumn{2}{|c|}{ Prevalence of MSDs } & \multirow{2}{*}{$\begin{array}{c}\text { Odds R } \\
(95 \% \text { CI })\end{array}$} & \multirow[b]{2}{*}{$\mathbf{X}^{2}$} & \multirow[b]{2}{*}{$\mathbf{p}$} \\
\hline & $\begin{array}{c}\text { Yes }(\mathrm{No}=269) \\
\text { No\% }\end{array}$ & $\begin{array}{c}\text { NO }(\mathrm{No}=134) \\
\text { No } \%\end{array}$ & & & \\
\hline \multicolumn{6}{|l|}{ Gender } \\
\hline Male $(\mathrm{No}=209)$ & $132(63.2) \%$ & $77 \quad(36.8) \%$ & \multirow{2}{*}{$\begin{array}{c}1.4020 \\
(0.923-2.128)\end{array}$} & \multirow[b]{2}{*}{2.5232} & \multirow[b]{2}{*}{0.112} \\
\hline Female(No = 194) & $137(70.6 \%)$ & $57 \quad(29.4) \%$ & & & \\
\hline \multicolumn{6}{|l|}{ Age } \\
\hline$<30$ y $(\mathrm{No}=320)$ & $198(61.9 \%)$ & $122(38.1) \%$ & \multirow{2}{*}{$\begin{array}{c}3.6456 \\
(1.892-6.997)\end{array}$} & \multirow[b]{2}{*}{16.632} & \multirow[b]{2}{*}{$0.001 * *$} \\
\hline 30 y or more $(\mathrm{No}=83)$ & $71 \quad(85.5 \%)$ & $12 \quad(14.5) \%$ & & & \\
\hline \multicolumn{6}{|l|}{ Job description } \\
\hline Students $(\mathrm{No}=171)$ & $100(58.5 \%)$ & $71 \quad(41.5 \%)$ & & \multirow{3}{*}{10.366} & \multirow{3}{*}{$0.005 *$} \\
\hline$\# \#$ H. officers $(\mathrm{No}=118)$ & $82(69.5 \%)$ & $36 \quad(30.5) \%$ & & & \\
\hline Staff $($ No $=114)$ & $87(76.3 \%)$ & $27 \quad(23.7) \%$ & & & \\
\hline \multicolumn{6}{|l|}{ \#\#\# BMI } \\
\hline $\operatorname{Normal}(\mathrm{No}=278)$ & $171(61.5 \%)$ & $107(38.5) \%$ & \multirow{2}{*}{$\begin{array}{c}2.2452 \\
(1.380-3.652)\end{array}$} & \multirow[b]{2}{*}{11.082} & \multirow[b]{2}{*}{$0.001 * *$} \\
\hline Overweight( $\mathrm{No}=125)$ & $98(78.4 \%)$ & $27 \quad(21.6) \%$ & & & \\
\hline \multicolumn{6}{|l|}{ Work experience } \\
\hline$<10$ years $($ No $=351)$ & $230 \quad(65.5 \%)$ & $121(34.5) \%$ & \multirow{2}{*}{$\begin{array}{c}1.578 \\
(0.8115-3.06)\end{array}$} & \multirow[b]{2}{*}{1.8312} & \multirow[b]{2}{*}{0.1759} \\
\hline $10 \mathrm{y}$ or more $(\mathrm{No}=52)$ & $39(75.0 \%)$ & $13(25.0) \%$ & & & \\
\hline
\end{tabular}

\#: Percentages were taken from the row\#\#: H. officers: House officers \#\#\#BMI: Body Mass Index

$*$ : Statistically significant at $\mathrm{p}<0.05 \quad$ * $\quad$ : Highly statistically significant at $\mathrm{p}<0.01$

Table (4) illustrated the association between MSDs in the past 12 months, personal and job characteristics and it showed that there was a highly statistically significant difference between the groups of dentists more than 30 years of age compared to others. Females had higher prevalence of MSDs compared to male's respondents, but without statistical significant differences. Dental staff $(76.3 \%)$ showed a statistically significant difference compared to dental students (58.5\%) and house officers $(69.5 \%) \mathrm{p}<0.05$. Overweight participants had more prevalence of MSDs compared to normal weight, and this association was highly statistically significant. Participants 
who worked 10 years or more were complaining from MSDs more than those who worked less than 10 years, but this relation was statistically non significant $(\mathrm{p}>0.05)$.

Table (5): Association between MSDs with physical and psychosocial risk factors.

\begin{tabular}{|c|c|c|c|c|c|c|c|}
\hline \multirow[b]{2}{*}{ Risk factors } & \multicolumn{2}{|c|}{ Prevalence of MSD } & \multirow{2}{*}{$\begin{array}{c}\text { OR } \\
\text { (CI 95\%) }\end{array}$} & \multirow[b]{2}{*}{$\mathrm{X}^{2}$} & \multirow[b]{2}{*}{$\mathbf{p}$} & & \\
\hline & $\begin{array}{c}\text { Yes(No=269) } \\
\text { No\% }\end{array}$ & $\begin{array}{c}\text { NO }\left(\mathrm{N}_{0}=134\right) \\
\text { No } \%\end{array}$ & & & & & \\
\hline \multicolumn{8}{|l|}{ A-Physical load } \\
\hline \multicolumn{8}{|c|}{ Use of vibrating tools } \\
\hline $\mathrm{NO}(\mathrm{No}=151)$ & $91 \quad(60.3) \%$ & $60(39.7) \%$ & \multirow{2}{*}{$\begin{array}{c}1.586 \\
(1.038-2.417)\end{array}$} & \multirow[b]{2}{*}{4.574} & \multirow[b]{2}{*}{$0.03 *$} & & \\
\hline $\mathrm{Yes}\left(\mathrm{No}_{0}=252\right)$ & $178(70.6) \%$ & $74(29.4) \%$ & & & & & \\
\hline \multicolumn{6}{|c|}{ Excessive arm elevation } & & \\
\hline \multicolumn{3}{|l|}{$\mathrm{NO}(\mathrm{No}=243)$} & $136(55.9) \%$ & $107(44.1) \%$ & \multirow{2}{*}{$\begin{array}{c}3.875 \\
(2.386-6.295)\end{array}$} & 32.06 & $0.01^{* *}$ \\
\hline Yes $\left(\mathrm{No}_{0}=160\right)$ & $133(83.1) \%$ & $27 \quad(16.9) \%$ & & & & & \\
\hline \multicolumn{8}{|c|}{ \#\#Prolong sit/stand } \\
\hline $\mathrm{NO}(\mathrm{No}=160)$ & $65(40.6) \%$ & $95 \quad(59.4) \%$ & \multirow{2}{*}{$\begin{array}{c}7.645 \\
(4.789-12.17) \\
\end{array}$} & \multirow[b]{2}{*}{81.59} & \multirow[b]{2}{*}{$0.01 * *$} & & \\
\hline $\mathrm{Yes}(\mathrm{No}=243)$ & $204(83.9) \%$ & $39(16.1) \%$ & & & & & \\
\hline \multicolumn{8}{|c|}{ Excessive hand tightening } \\
\hline $\mathrm{NO}(\mathrm{No}=185)$ & $126(68.2) \%$ & $59(31.8) \%$ & \multirow{2}{*}{$\begin{array}{c}0.892 \\
(0.588-1.354)\end{array}$} & \multirow[b]{2}{*}{0.284} & \multirow[b]{2}{*}{0.59} & & \\
\hline $\mathrm{Yes}(\mathrm{No}=218)$ & $143(65.6) \%$ & $75(34.4) \%$ & & & & & \\
\hline \multicolumn{8}{|c|}{ Back bent or twist } \\
\hline $\mathrm{NO}(\mathrm{No}=165)$ & $111 \quad(67.3) \%$ & $54 \quad(32.7) \%$ & \multirow{2}{*}{$\begin{array}{c}1.0062 \\
(0.658-1.537)\end{array}$} & \multirow[b]{2}{*}{0.034} & \multirow[b]{2}{*}{0.85} & & \\
\hline $\mathrm{Yes}\left(\mathrm{No}_{\mathrm{o}}=238\right)$ & $158(66.4) \%$ & $80(33.6) \%$ & & & & & \\
\hline \multicolumn{8}{|c|}{ B-Psychosocial load } \\
\hline \multicolumn{8}{|l|}{ Work demand } \\
\hline \multicolumn{2}{|c|}{ Low job demand(No =159) } & $106(66.7) \%$ & $53 \quad(33.3) \%$ & \multirow{2}{*}{$\begin{array}{c}1.0062 \\
(0.658-1.537) \\
\end{array}$} & \multirow[b]{2}{*}{0.0008} & \multirow[b]{2}{*}{0.97} & \\
\hline High job demanc & No = 244) & $\begin{array}{ll}163 & (66.8)\end{array}$ & $81 \quad(33.2) \%$ & & & & \\
\hline \multicolumn{8}{|l|}{ Work control } \\
\hline \multicolumn{2}{|c|}{ Bad job control $\quad(\mathrm{No}=192)$} & $157(81.8) \%$ & $\begin{array}{|ll|}35 & (18.2) \% \\
\end{array}$ & 0.2522 & & & \\
\hline Good job contro & No $=211)$ & $112(53.1) \%$ & $99(46.9) \%$ & $(0.600-0.397)$ & 37.28 & $0.01 * *$ & \\
\hline
\end{tabular}

\#: Percentages were taken from the rows \#\#: Prolong sit/ stand: Prolonged sitting/ standing

*: Statistically significant at $\mathrm{p}<0.05 \quad * *$ : Highly statistically significant at $\mathrm{p}<0.01$ 
Table (5) showed that among the physical risk factors studied: using vibrating tools, excessive arm elevation and prolonged sitting / standing; increased the risk of musculoskeletal disorders among participants $\mathrm{p}<0.05$. Among the psychosocial risk factors studied; only poor job control significantly increased the risk of MSDs $(\mathrm{p}<0.05)$.

\section{Discussion}

Work related MSDs are one of the main occupational health hazards affecting dental practitioners and dental students (Leggat et al., 2007) .This study highlights and supports the established fact that MSDs are major concern for dental staff and students during their professional career.

In the present study; $66.7 \%$ of the respondents were reporting development of some musculoskeletal pain in the past 12 months (Table 2). This prevalence was similar to that found by previous Egyptian study done by Ahmed and Orabi, 2017, on work related musculoskeletal disorders among dentists in Sharkia Governmental Hospitals, and they found that $66.8 \%$ of their studied group was complaining of MSDs. Also it was in agreement with a study done by Ali and Hashim, 2012 on occupational health problems among dentists in the United Arab Emirates and they detected that $68.1 \%$ had MSDs. But our results were higher than that reported by dental practitioners in other studies (37\%) (Leggat and Smith, 2006), (60\%) (Al Wazzan et al., 2001) and (58.5\%) (Hassan et al., 2017).Also; Milerad and Ekenvall, 1990, reported higher prevalence of MSDs among dentist than pharmacists.

Findings in the present study showed that neck and shoulder area were the most prevalent region of pain $(66.5 \%$ and $61.8 \%)$ respectively ,while the second highest region of pain was the lower back (59.3\%) (Table2). Similar results were reported by previous Egyptian study done by Hegazy et al.,2009 on the prevalence of musculoskeletal complaints among dentists in some Egyptian cities and concluded that $(75.1 \%)$ of their studied group were complaining of neck pain and $(58.5 \%)$ of lower back pain. Also our work was in accordance with a study done on Danish dentists were $(65 \%)$ of them suffered from neck/ shoulders pain and (50\%) from lower back pain (Fensin et al.,1998 ).On the contrary, Szymanska (2002) and Pureine et al , (2008) reported that 
MSDs of lower back was the most prevalent musculoskeletal complaint among dentists.

In addition, (46.2\%) of the participants in the current study reported hand/wrist pain (Table 2) which was similar to that reported by Hegazy et al., 2009 on their study among Egyptian dentists and found that (47.4\%) were complaining of hand/wrist pain. But our results were higher than that detected by Leggat and Smith, 2006 in their Australian study (31\%) and less than that reported by United Stated military study (75\%) (Rice et al., 1996). An explanation for the high prevalence of MSDs in the neck, shoulder and lower back region among dentists is that most of the dental practitioners adopt positions that cause high load on the trapezius muscle bilaterally along with prolonged forward bending of the back and neck which result in muscular spasm, fatigue and pain (Milerad and Ekenvall, 1990).

In the current study; MSDs were seen to be an ongoing problem in about one third $(29.3 \%)$ of the respondents suffering from chronic pain that lasted more than one month (Table2).This is almost similar to the findings of Evangelos and his colleagues., 2004 who reported chronic low back pain among $25 \%$ of dentists.

MSDs affect the physical, psychological and social aspects of dental practitioners; this is in turn has an impact on their productivity and ultimately reducing their quality of life (Smith et al., 2006). In the present study, over a period of 12 months, MSDs has affected our participants as evident from the reduction in their work performance by $(24.2 \%)$, reduction in daily activities by $(30.1 \%)$, taking analgesic by $(24.2 \%)$, hospitalization and surgical interference by (4.5\%) (Table3). These findings were relatively similar to the study done by Brown et al., 2010 on their work on dental practitioners who reported sickness absence, changing the work setting, and even claiming compensation as the outcome of MSDs. This impact demonstrates the need for determining protective interventions to limit the prevalence of MSDs in the profession.

In the current study; only (8.6\%) of the studied subject had to go on sick leave because of musculoskeletal complaints (Table3). This figure is approximately similar to that declared by Marshall et al., 1997 on their study on musculoskeletal symptoms in New 
Wales dentists and found that $10 \%$ of the Australian dental practitioners were asking for sick leave. But much lower than that reported by Alexopoulos et al., 2004 (24\%) and Hegazy et al., 2009 $(27.4 \%)$.

As regard the association between personal and job characteristics and the occurrence of MSDs; dentists more than 30 years old were more prone to develop musculoskeletal complaints (Table4). Similar results were detected in other studies among dental practitioners in Lithuania and Poland ( Puriene el al.,2007 and Puriene et al 2008 ). In addition; another study in Australia showed that older dentists reported more neck, upper back and shoulder pain compared to others. Authors of the last study detected that older dentists treat more patients per day with more working hours (Moen and Jorvatn, 1996). In contrast to our findings, other studies among dentists in New South Wales and in Saudi Arabia showed prevalence of MSDs decreases with older age (Marshall et al., 1997 and Abduljabbar, 2008).

In the current work; the overall prevalence ofMSDs in the past 12 months was higher in female group compared to males but without statistically significant differences (Table 4). Two studies conducted in Lithuania (Puriene et al; 2008) and New Zealand (Ayers et al; 2009) revealed higher prevalence of MSDs among female practitioners. This is can be attributed to the gender difference in muscular capacity. These results might have implications on the female work productivity. It has been reported that more women than men reported sickness absenteeism due to musculoskeletal complaints (Ayres et al., 2009).

An interesting finding in this study was that the majority of dental staff (76.3\%) suffered from MSDs compared to $(69.5 \%)$ among house officers and (58.5\%) among dental students and it was statistically significant (Table 4). The high prevalence of MSDs in our sample is either due to overload in the work setting, faulty ergonomics, or incorrect techniques used during treatment of patients. This finding was in agreement with a study conducted in Turkey which revealed high prevalence of pain among dental staff in the form of neck pain $(67 \%)$ and back pain $(56 \%)$ (Tezel et al., 2005) .Also; another study from USA carried by Rising et al.,2005 , reported that almost $65 \%$ of dental students suffered from muscular pain in 
their third year. It is worth mentioning that if dental students suffer pain early in their lives; the problem could grow, making it difficult for them to practice in the future.

In the current work; significant relations were found between some selfreported physical risk factors and the occurrence of MSDs in various body sites. Prolong sitting or standing during work played a significant important role as a risk factor for the development of work related MSDs $(\mathrm{p}<0.05)$ (Table 5 ). Similar result was detected by (Pope et al., 2002) who concluded that those working in sitting position only for prolonged hours had more severe low back pain than those who alternated between sitting and standing positions. Standing or sitting for long periods can result in chronic muscular fatigue, pain or discomfort (Pandis et al., 2007). So it's highly recommended for dentists to change their work postures frequently. MSDs were also significantly associated with the use of vibrating tools $(\mathrm{p}<0.05)$ (Table 5). This was consistent with Alexopoulos et al., 2004 who detected that the use of vibration tool and excessive bending or twisting low back were the most significant physical factors that caused MSDs among dentists.
As regard to psychosocial factors, the practice of dentistry was perceived as requiring high levels of mental demand and high control over the job, a perception shared by Swedish dentists (Akesson et al., 1999). In the present study, poor job control was a significant risk factor for the development of MSDs $(p<0.05) \quad($ Table 5).This was similar to the work done by Alexopoulos et al 2004 who reported that MSDs were more prevalent among those with lower job control.The current study demonstrated that there was no association between high job demand and the occurrence of MSDs ( $p>0.05$ ) (Table5), which was in contrast to (Bongers et al., 2002) who found a higher prevalence of musculoskeletal pain among dentists with high perceived job demand, they concluded that high job demand increases the muscle strain and decreases the ability to cope with the symptoms. Further; Delp and Wang, 2013 reported that tight work schedule and working more than $2 \mathrm{~h}$ without a break was strongly associated with neck and back pain.

\section{Conclusion and recommendations:}

Work related musculoskeletal disorders (MSDs) are significant occupational health problems among both dentists 
and dental students. Their medical consequences justify extensive preventiveefforts. Interactionof physical load, psychosocial load, personal and job characteristics in developing MSDs require integrated preventive strategies. Specific occupational health education programs, including ergonomic workplace adaptation should be implemented to decrease the prevalence of work related MSDs among dental professionals, so that can effectively take care of patient and focus on their work. Also; it is recommended that ergonomics should be covered and taught as part of the dental curriculum to reduce risks of work related MSDs in the future.

Study limitations : The study findings were based on self-reported information provided by participants and some potential for reporting bias may have occurred. Also this study was limited to only one institute and reports cross sectional data; further research using a prospective design is recommended

\section{Conflict of interest}

There was no conflict of interest.

\section{Funding}

None.

\section{References}

1. Abduljabbar TA (2008): Musculoskeletal disorder among dentists in Saudi Arabia, Pakistan Oral and dental journal ;28 (1):135-44

2. Ahmed AS and Orabi EE (2017): Work related musculoskeletal disorders among dentists in Sharkia Governmental hospitals, Egypt. Egypt J Occup Med;41(2): 175-86

3. Al-Ali K and Hashim R (2012): Occupational health problems of dentists in the United Arab Emirates. Int Dent J; 62(1):52-6.

4. Alexopoulos E, Stathi I and Charizani F (2004): Prevalence of musculoskeletal disorders in dentists. BMC Musculoskelet Disord ; 9:5-16.

5. Al Wazzan KA, Almas K, Al Sheethri SE and Al-Qahtani MQ (2001): Back and neck problems among dentists and dental auxiliaries. J Contemp Dent Pract; 2:17-30.

6. Akesson I, Moritz U and Skerfving S (1999): Musculoskeletal disorders among female dental personnel-clinical examination. Int Arch Environ Occup Med; 72: 395-403.

7. Andersson GB (1999): Epidemiological features of chronic low-back pain. Lancet; 354: 581-585.

8. Ayers KM, Omson WM, Newton T, Morgaine KC and Rich AM (2009): Selfreported occupational health of general dental practitioners. Occupational Medicine;59 (3):142-8

9. Bongers PM, Kremer A and Laak J (2002): Are psychosocial factors, risk factors for symptoms and signs of the shoulder, elbow, or hand/wrist? Am J Ind Med;41:315-42

10. Brown J, Burke F, Macdonald E and Murray K (2010): Dental practitioners and ill health retirement: causes, outcomes and reemployment. Br Dental J; 209(10):488 -81

11. Delp L and Wang PC (2013): Musculoskeletal disorders among clerical workers in Los Angeles: a labor management approach. Am J Ind Med;56:1072-81

12. Diaz Aj-Caballero and Díaz-CD IP (2010): 
Ergonomic factors that cause the presence of pain muscle in students of dentistry. Med Oral Patol; 15 :906-911

13. Evangelos C, Alexopoulos EC, Stati IC and Charicani F (2004): Prevalence of musculoskeletal disorders in dentists. Int Arch Occup Environ Health; 76(4):289-94.

14. Finsen L, Christensen H and Bakke M (1998): Musculoskeletal disorder among dentists and variation in dental work. Appl Ergon; 29(2):119-25.

15. Hakkanen M, Viikari-Juntura E and Martikainen R (2001): Job experience, work load, and risk of musculoskeletal disorders. Occup Environ Med;58:129-135

16. Hassan EE, Elkhateeb A, Ewis A and Ali A (2017): Musculoskeletal disorders among dentist and physicians at Menia university hospital. Egypt J Occup Med;41(1):55-70

17. Hayes M, Cockrell D and Smith DR (2009); A systematic review of musculoskeletal disorders among dental professionals. Int J Dent Hyg; 7:159-65.

18. Hegazy AA, Awadalla NJ and Shenouda NS (2009); Prevalence of musculoskeletal complaints among dentists in some Egyptian cities. Egypt J Occup Med 33(1):55-71

19. Karasek R, Brisson C, Kawakami N and Amick B (1998): The job content questionnaire (JCQ): an instrument for internationally comparative assessments of psychosocial job characteristics. J Occup Health Psych;3:322-355

20. Kuorinka I, Jonsson B and Kilbom A (1987): Standardized Nordic questionnaires for the analysis of musculoskeletal symptoms. Appl Ergon ; 18 :233-37

21. Leggat PA, Kedjarune U and Smith DR (2007): Occupational health problems in modern dentistry. Ind Health; 45: 611-21.

22. Leggat PA and Smith DR (2006): Musculoskeletal disorders self- reported by dentists in Queensland, Australia. Austr Dent J; 51 (4): 324-7

23. Marshall E, Duncombe L, Robenson R and
Killbreath S (1997): Musculoskeletal symptoms in new wales dentists. Austr Dent J;42 (4):24064

24. Milerad E and Ekenvall L (1990): Symptoms of the neck and upper extremities in dentists. Scand J Work Environ Health; 16: 129-34.

25. Moen BE and Bjorvatn K (1996): Musculoskeletal symptoms among dentists in dental school. Occup Med J; 46:65-6

26. Morse T, Bruneau H and Turcotte C (2007): Musculoskeletal disorders of the neck and shoulder in dental hygienists and dental hygiene students. J Dent Hyg; 81(1):10

27. Pandis N, Pandis BD and Eliades T (2007): Occupational hazards in orthodontics; review of risks and associated pathology. Am J Orthod ;32: 280-92

28. Pope M, Goh K and Magnusson M (2002): spine ergonomics; Annu Rev Biomed Eng;4:49-68

29. Puriene A, Balciuniene I and Tutkuveien J (2008): Specificity of chronic self-reported occupational hazards among male and female Lithuanian dentists. Acta Medica Lithuania;4:55-60

30. Puriene A Janulyte V, Musteikyte $M$ and Bendinskaite R (2007): General health of dentists. Literature review Stomatologija;9 (1): 10-20

31. Rice VJ, Nindl B and Pentikis JS (1996): Dental workers, musculoskeletal cumulative trauma, and carpal tunnel syndrome, who is at risk? Int $\mathrm{J}$ Occup Saf Ergon; 2: 218-233.

32. Rising DWI, Bennett BC, Hursh K and Plesh O (2005): Reports of body pain in a dental students population. J AM Dent Assoc; 36(1):81-6

33. Samotoi A, Moffat SM and Thomson WM (2008): Musculoskeletal symptoms in New Zealand dental therapists: prevalence and associated disability. N Z Dent J ; 104:49-53

34. Shikdar AA and Sawaqed NA (2004): Ergonomics, and occupational health and safety in the oil industry: A managers $>$ response. Comp Ind Eng; 47:223-32.

35. Smith DR, Wei N, Zhang Y and Wang R (2006): 
Musculoskeletal complaints and psychosocial risk factors among physicians in China. Int J Ind Ergon; 36: 599-603

36. Szmanska J(2002): Disorders of musculoskeletal system among dentists from the aspect of ergonomics. Ann Agr Env Med; 9 (2):169-173

37. Tezel A, Kavrut F, Tezel A, Kara C, Demir T, et al. (2005): Musculoskeletal disorders in lift-right handed Turkish dental students. Int $\mathbf{J}$ Neurosci;115(2): 255-66

38. Udoye CI and Aguwa EN (2007): Musculoskeletal symptoms: a survey amongst selected Nigerian dentists. Int J Dent Sci; 5:1-5.

39. Yousef MK and Al-Zain AO (2009): Posture evaluation of dental students. JKAU Med Sci:16:51 